\title{
How much does community-based targeting of the ultra-poor in the health sector cost? Novel evidence from Burkina Faso
}

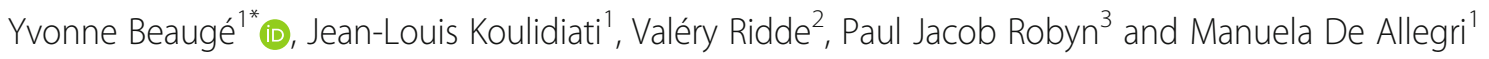

\begin{abstract}
Background: Targeting efforts aimed at increasing access to care for the poorest by reducing to a minimum or completely eliminating payments at point of use are increasingly being adopted across low and middle income countries, within the framework of Universal Health Coverage policies. No evidence, however, is available on the real cost of designing and implementing these efforts. Our study aimed to fill this gap in knowledge through the systematic assessment of both the financial and economic costs associated with designing and implementing a pro-poor community-based targeting intervention across eight districts in rural Burkina Faso.
\end{abstract}

Methods: We conducted a partial retrospective economic evaluation (i.e. estimating costs, but not benefits) associated with the abovementioned targeting intervention. We adopted a health system perspective, including all costs incurred by the government and its development partners as well as costs incurred by the community when working as volunteers on behalf of government structures. To trace both financial and economic costs, we combined Activity-Based Costing with Resource Consumption Accounting. To this purpose, we consulted and extracted information from all relevant design/implementation documents and conducted additional key informant structured interviews to assess the resource consumption that was not valued in the documents.

Results: For the entire community-based targeting intervention, we estimated a financial cost of USD 587,510 and an economic cost of USD 1,213,447. The difference was driven primarily by the value of the time contributed by the community. Communities carried the main economic burden. With a total of 102,609 ultra-poor identified, the financial cost and the economic cost per ultra-poor person were respectively USD 5,73 and USD 11,83.

Conclusion: The study is first of its kind to accurately trace the financial and economic costs of a community-based targeting intervention aiming to identify the ultra-poor. The financial costs amounted to USD 5,73 and the economic costs to USD 11,83 per ultra-poor person identified. The financial costs of almost USD 6 represents 21\% of the per capita government expenditure on health.

Keywords: Community-based targeting, Targeting, Ultra-poor, Pro-poor targeting, Activity-based costing, Burkina Faso, Costs, Economic evaluation

\footnotetext{
* Correspondence: yvonne.beauge@uni-heidelberg.de

${ }^{1}$ Institute of Public Health, Medical Faculty, Heidelberg University, Heidelberg,

Germany

Full list of author information is available at the end of the article
}

(c) The Author(s). 2018 Open Access This article is distributed under the terms of the Creative Commons Attribution 4.0 International License (http://creativecommons.org/licenses/by/4.0/), which permits unrestricted use, distribution, and reproduction in any medium, provided you give appropriate credit to the original author(s) and the source, provide a link to the Creative Commons license, and indicate if changes were made. 


\section{Key messages}

- This study fills an important knowledge gap on cost of community-based selection and targeting interventions

- Financial costs associated with community-based targeting in Burkina Faso amounted to USD 5,73 and the economic costs to USD 11,83 per ultra-poor person identified

- Economic costs amounted to USD 1,213,447 including the value of the effort contributed by volunteers, exceeding by two-folds the financial costs of USD 587,510

\section{Background}

Universal Health Coverage (UHC) aspires to provide affordable and quality health care to all [1]. However, many low and middle income countries (LMICs) continue to rely on user fees which severely limits access to care and use of health services, especially for the poorest segments in a society [2]. In order to protect the most vulnerable people from financial hardship, some countries have opted for exempting the poorest from user fees [3] or for subsidizing health insurance premiums [4]. The identification and selection of the poor for user-fee exemption or insurance premium subsidization has been proven to be very challenging [5].

In the absence of universal criteria to define poverty and identify the poorest, countries have traditionally adopted various targeting methods. In the literature, the identification of beneficiaries is presented as the process of selecting the persons that benefit from a certain intervention. Targeting, on the other hand, is commonly used as a broader term which includes the identification as well as the actual act of allocating scarce resources to the poorest with the aim of achieving certain policy objectives to preserve or improve health equity [6].

In the health sector, most targeting experiences derive from those with the greatest health risks or the highest ability to benefit from the programs [7]. Those are generally the poorest [8] but can also be other groups of people such as the elderly, orphans or people with disabilities [9].

Generally, high-income countries use a form of means-testing and identify ultra-poor based on a certain income threshold. On the contrary, targeting strategies without a direct observation of income, such as proxy means testing (PMT) and community targeting, are predominantly used in LMICs [6]. While PMT uses a formal algorithm to identify households' wealth, community based targeting (CBT) collects information from local leaders [10].

All targeting mechanism are prone to errors and generate costs [11]. Various studies have shown that there is no best solution to identify beneficiaries for targeting health benefits. Relative accuracy and cost effectiveness are said to be best achieved by a well-designed and implemented mechanism [9]. However, the scientific community continues to debate the relative costs and benefits of universal vs. targeted strategies in allocating resources to the poorest and alleviating poverty [12-14]. The question is whether the costs associated with the CBT program actually compensate for the savings accrued when offering subsidized or free health services only to a selected number of individuals.

These arguments are mostly postulated in the light of theoretical assumptions on the costs and benefits associated with targeting procedures, but are not substantiated by any extensive empirical evidence [15]. The literature suggests that CBT can potentially contribute to a reduction in administrative costs compared to other targeting methods $[8,16,17]$, since the bulk of resources, such as time and expertise, are provided by community members who are usually not remunerated. Prior studies [18, 19] addressed the costs of pro-poor targeting programs briefly by focusing on the financial expenses and showed that engaging the poor to identify the poorest is not costly. However, both studies disregarded, amongst other components, the time volunteers (e.g. community members) invested into the targeting exercise. Prior studies which addressed the effectiveness of pro-poor targeting showed inconsistent results [20-23]. These evaluations have focused primarily on estimating how effective programs are in relation to how well all members of a certain target group are included, and members of the non-target group excluded from participating in a targeted program [20-22]. The available evidence, however, is almost completely silent as to whether targeting policies for the poor offer good value for money, as measured in terms the relationship between their costs and their benefits.

Towards this ends, our economic evaluation began to fill an important gap in knowledge by assessing both the financial and the economic costs associated with designing and implementing a pro-poor targeting project, with specific focus on the identification and targeting component integrated within the Performance Based Financing (PBF) intervention recently rolled out in Burkina Faso [24]. We plan to include these first cost estimates into more comprehensive cost-effectiveness analysis of propoor targeting policies in the future.

\section{Methods}

\section{Study setting}

This study took place in Burkina Faso, where a PBF intervention was launched in 2014 under coordination of the Ministry of Health $(\mathrm{MoH})$ with financial support from the Health Results Innovation Trust Fund 
(HRITF), administered by the World Bank (WB). The Programme d'Appui Au Développement (PADS), Burkina Faso's initiative to better coordinate and manage resources for the implementation of the National Health Development Plan, channeled the funding provided by the HRITF to the CBT intervention. The Society for Studies and Public Health Research (SERSAP), a for-profit consultancy firm, led the implementation of the CBT intervention. The objective of the intervention is to combine a supply-side (PBF) with a demand side (subsidy for the poorest) component to maximize health gains for the poorest. [25] In eight out of a total of 12 districts implementing PBF, healthcare providers receive payments based on a fixed unit price per service, plus a lump-sum to reimburse (at the expected average cost of treatment) for loss of income due to loss of user fees, by treating the ultra-poor for free. Thereby, it is ensured that health facilities are not disadvantaged by delivering care to the ultra-poor who do not pay the health providers directly [26].

The process of selecting and identifying the ultra-poor by community members, including the design and implementation of the structures, lasted from May 2014-January 2016. Across the eight districts, it covered $1,745,789$ individuals, i.e. approximately $10 \%$ of the country's total population (18.1 million) [27]. Additional file 1 provides details on the organization of the CBT selection process, under leadership by SERSAP. A total of 1172 Community Selection Committees (CSI) (gender-balanced) were set up across the eight districts at the village level to select the ultra-poor based on their profound knowledge of the population, and establish lists of the ultra-poor. The CBT selection processes were guided by the definition of an ultra -poor (indigent) person as "someone who is extremely socially and economically disadvantaged, unable to care for himself (herself) and who is without internal or external resources" [20] and was meant to result in the compilation of community-specific lists of the ultra-poor as individuals eligible to benefit from a user fee exemption.

The lists of the ultra-poor persons were verified by two entities, the Local Implementation Teams (ELMEO) and the Local Validation Groups (GVL). For this validation process, the respective teams used a list of 20 ultra-poor criteria which were initially developed in the context of the action research done in one district in Burkina (Ouargaye) [28]. The ELMEO randomly selected people from the list and verified whether these criteria were respected (external validation), before handing the list over to the GVL. The GVL then went through the entire list and checked whether each selected person fulfilled the ultra-poor criteria, then confirmed or rejected their ultra-poor status (internal validation). The WB developed a database of the ultra-poor in order to compile detailed information about them (e.g. village, full name, age, gender). Thirty-five enumerators collected these data, including digital pictures of the ultra-poor. The information was used to issue identity cards (produced in Vietnam) that had to be shown in order to receive basic primary, secondary and tertiary health care free of charge (fees and drugs) at all public health facilities within the implementation districts of the PBF [29].

Monitoring and Evaluation (M\&E) was secured by the ELMEO, the Regional Directorate for Health and Social Action and the Regional Technical Assistants (ATR). Originally, it was envisioned that 15 to $20 \%$ of the population will be targeted and exempted from user fee payment. On average $6 \%$ of the total population were finally identified as the ultra-poor [29].

\section{Study design and conceptual approach}

We conducted a retrospective partial economic evaluation [30] with the objective of estimating both the financial and the economic costs of the abovementioned community-based identification and targeting of the ultra-poor. We refer to our work as a partial economic evaluation, since we focused exclusively on documenting costs and not on establishing a relationship between the costs and consequences of the intervention. This decision is linked to two factors. First, we wanted to focus exclusively and carefully on the cost component to fill the important gap in knowledge on the real cost of targeting outlined earlier. Second, at the time of our study, the intervention was ongoing; hence, it was not yet possible to determine the extent to which targeting had actually contributed to an increase in health service utilization among the poorest and the related health service provision costs. Hence, we traced costs for the design phase (May 2014-August 2014) and the implementation phase (September 2014-January 2016), defining as implementation only the process of identifying and selecting the ultra-poor, not of providing healthcare services to them.

As financial costs (accounting costs), we defined all explicit financing transactions made by any of the concerned actors to carry out any activity related to either the design or the implementation of the intervention. These costs can be verified retrospectively on the accounting systems of the implementing agencies. As economic costs, we defined the real value of the resources consumed by the intervention.

We adopted a health system perspective, meaning that we aimed at tracing all costs incurred by the $\mathrm{MoH}$ and its partners, including development partners and implementing agencies. Costs incurred at the community level were included in the analysis insofar as the community was engaged as a volunteer agent to act on behalf of the Ministry as a formal implementing partner, effectively carrying out/substituting key intervention functions. 
To trace both financial and economic costs, we combined Activity-Based Costing (ABC-approach) with Resource Consumption Accounting. ABC aggregates costs by activity, attributing indirect and support expenses to the individual activities [31]. Resource Consumption Accounting first itemizes (identification) and measures (measurement) the resources necessary to carry out a given activity and then values (valuation) the consumption of each resource for service provision and calculating or estimating the costs of each resource [32].

\section{Data collection}

We carried out data collection over a period of six months from October 2016 to March 2017. We computed all costs in US dollars (USD), adjusting for inflation from the year in which the costs were incurred to the year 2015. We used the average exchange rate for the period May 2014 to January 2016 to convert values from FCFA (Central French African Francs) to USD (1 FCFA = USD 0.00164 in 2014; USD 0.00168 in 2015; USD 0.00167 in 2016).

In line with the conceptual approach described earlier, data collection reflected three steps: identification, measurement and valuation.

\section{Step 1: Identification}

We started the data collection by asking the main stakeholders $(\mathrm{MoH}$ and $\mathrm{WB})$ and implementing actors from the central level to share planning and implementation documents with us, including financial statements (e.g. initial budgets, project reports), that would allow us to reconstruct all activities carried out from the moment the intervention was conceived to the moment the identification cards were distributed to the ultra-poor. We examined all project documents in order to generate a detailed list of activities, including those of the main stakeholder as well as of the different implementation actors involved at each and every stage of the design and implementation phase (Table 1). This process allowed us to identify additional actors beyond those working directly for one of the agencies who had actively led design and/or implementation activities (such as development partners, academics, and consultants).

\section{Step 2: Measurement}

To estimate resource use, we triangulated information across data sources and filled gaps that emerged as we progressed through the data by conducting a series of face-to-face key informant interviews. We interviewed the two central level coordinators employed at SERSAP and the four regional coordinators. We used structured interview forms to ask respondents to recall the time spent by the various actors, including communities, on design and implementation activities (Additional files 2, 3 and 4). In addition, we asked key WB staff, academics, and consultants to estimate their time commitment to the program (interviews done by phone and/or email) (Additional file 5). WB staff was also instrumental in identifying material resource consumption, for instance in relation to the production of the cards.

\section{Step 3: Valuation}

We first quantified the units of each resource and multiplied them by its unit costs. Reconstructing the intervention's financial costs, for both personnel and material resources, was a relatively straightforward process, as financial transactions related to the intervention could easily be reconstructed by combining financial statements by SERSAP, PADS and the WB. Reconstructing the intervention's economic costs was a more complex process. Material resources that could not be traced in

Table 1 List of activities (aggregated)

\begin{tabular}{|c|c|}
\hline List of Core Activities (aggregated) & Description \\
\hline $\begin{array}{l}\text { 1. General Coordination/Management } \\
\text { Design Phase }\end{array}$ & $\begin{array}{l}\text { - All general activities performed during the design of the process (e.g. initial workshops to define the targeting } \\
\text { strategy, seminars to develop the concept note, internal workshops hold by SERSAP }\end{array}$ \\
\hline $\begin{array}{l}\text { 2. General Coordination/Management } \\
\text { Implementation Phase }\end{array}$ & $\begin{array}{l}\text { - All general coordination, management and supervision activities performed during the implementation } \\
\text { phase (e.g. informational meetings at central, regional and district level and the national launch of the } \\
\text { targeting intervention) }\end{array}$ \\
\hline 3. Training & - Training of ELMEO, CSS, GVL, CSI and the enumerators \\
\hline 4. Selection of the ultra-poor & $\begin{array}{l}\text { - All activities related to the actual selection of in the villages (e.g. CSI meetings to select the ultra-poor and } \\
\text { to establish lists, validation sessions by GVL to validate lists etc.) }\end{array}$ \\
\hline 5. Data Collection & $\begin{array}{l}\text { - Development of the data collection program and questionnaires, preparation of tablets, data collection by } \\
35 \text { enumerators in the villages, photo taking and management of the ultra-poor database } \\
\text { - Community members supported the enumerators to locate selected and assisted during data collection }\end{array}$ \\
\hline 6. Card Production/Distribution & $\begin{array}{l}\text { - Every ultra-poor person received a personalized identity card to receive free services at health facilities } \\
\text { - A Vietnamese IT company produced the ID cards and shipped them to Burkina Faso }\end{array}$ \\
\hline 7. $M \& E$ & - All monitoring and quality control activities \\
\hline
\end{tabular}


the financial records, such as donated vehicles or donated supplies, were valued using current market prices, for instance average vehicle rental and average room rental prices. We used the human capital approach (according to which value of time is measured through the earnings of an individual [30] to value the time of personnel who contributed to design and/or implementation without being directly compensated for it. Specifically, we valued: 1 . the time of $\mathrm{MoH}$ staff using average earnings for the different civil servant cadres [33]; 2. the time of community members using minimum daily wage (USD 2.31) [34]; 3. the time of all international development partners and consultants using standard WB consultancy rates (300 USD a day for a mid-career consultant and 600 USD a day for a senior consultant).

\section{Data analysis}

First, keeping the differentiation between financial and economic costs and differentiating between the design and the implementation phase, we aggregated cost information by activity and by cost category. To simplify reading and facilitate understanding, we aggregated single activities into broad analysis categories by combining conceptual analogous activities. In addition, we aggregated costs by single actor by carefully assessing where expenses were really incurred. Then, we computed both financial and economic cost per ultra-poor person selected. As a final step, to test how the value of the intervention may change depending on variations in the cost of individual items, we conducted one-way sensitivity analyses, varying the percentage of overhead costs, the wage for informal workers and the budget provided by SERSAP including the costs for personnel, equipment, selection process and data collection. Additional file 6 provides an additional analysis of the financial and economic costs, first broken down by fixed and variables costs. The single activities with their costs are then assigned to the respective organizational level of the targeting program (national, regional, district, CSPS, village and indigent). The annex further provides cost functions which can be applied to estimate the total financial and economic costs for potential expansions of the program.

\section{Ethical considerations}

Ethical clearance was granted by both the Ethics Committee of Heidelberg University (protocol S-272/2013) and by the Comité National d'Éthique pour la Recherche en Santé (CNERS) in Burkina Faso (protocol number 2013-7-066 and 2017-9-138). All parties linked to the intervention agreed on processing the data for this study. Information from informants was obtained anonymously.

\section{Results}

Table 2 presents the financial and economic costs of the CBT intervention across activity clusters by phase. The estimated financial costs accounted for USD 587,510 and represent about $48 \%$ of the total economic value. The total economic cost of the CBT intervention was USD 1,213,447 The selection process represents the most relevant economic cost component. With an estimated economic value of USD 392,060 the selection of the ultra-poor carried out by community members represents one third of the total value of the intervention, followed by the data collection step with an estimated value of USD 328,958.

With a total of 102.609 identified ultra-poor persons, the financial costs amounted to USD 5,73 and the total economic costs to USD 11,83 per identified ultra-poor person.

\section{Distribution of financial and economic costs by actor}

Sixty percent of the total financial costs (=USD 350,704) were incurred by activities carried out by the implementation agency. Forty percent of the financial costs $(=\mathrm{USD}$

Table 2 Financial and economic costs by activity cluster (in USD)

\begin{tabular}{lllll}
\hline Activity & Financial Costs & Percentage (\%) & Economic Costs & Percentage (\%) \\
\hline $\begin{array}{l}\text { Design Phase } \\
\text { General Coordination \& Management }\end{array}$ & 6599 & $1 \%$ & 62,174 & $5 \%$ \\
$\begin{array}{l}\text { Implementation Phase } \\
\text { General Coordination \& Management }\end{array}$ & 23,350 & $4 \%$ & & \\
Training & 86,298 & $15 \%$ & 63,177 & $5 \%$ \\
Selection of the ultra-poor & 85,162 & $14 \%$ & 159,824 & $13 \%$ \\
Data Collection & 187,948 & $32 \%$ & 392,060 & $32 \%$ \\
Card Production \& Distribution & 107,000 & $18 \%$ & 328,958 & $27 \%$ \\
M\&E & 11,339 & $2 \%$ & 116,101 & $10 \%$ \\
$\quad$ Overhead (13\% SERSAP, 20\% WB) & 79,814 & $14 \%$ & 11,339 & $1 \%$ \\
Total & 587,510 & $100 \%$ & 79,814 & $7 \%$ \\
\hline
\end{tabular}


$236,807)$ came about due to activities performed by the WB.

Figure 1 shows the distribution of economic costs by actor. The highest proportion of economic costs were incurred at the community level (43\%), followed by the implementation agency (30\%) and the WB (25\%). Only $\leq 1 \%$ of the economic costs was due to activities performed by external consultants, Non-governmental organizations (NGOs) and ministries.

\section{Financial and economic costs - Design phase by cost categories across activity clusters}

Table 3 shows the financial and economic costs by cost categories for the activity "General Coordination \& Management" performed at the design phase of the CBT intervention. The total amounted to USD 7457 financial costs and USD 63,032 economic costs, including the overhead costs. More than $80 \%$ of the financial costs and more than $70 \%$ of the economic costs were due to human resource expenses.

\section{Financial and economic cost implementation phase by cost categories across activity clusters}

Table 4 shows the financial and total economic costs by cost categories across all activities performed during the implementation phase of the CBT intervention. The total amounted to USD 580,053 financial costs and USD $1,150,415$ economic costs including the overhead costs. Just like in the design phase of the intervention, human resources accounted for the largest portion of implementation costs - almost $50 \%$ of the financial costs and $72 \%$ of the total economic costs (Figs. 2 and 3 ). With USD 378,284, the biggest proportion of human resources was spent on the selection of ultra-poor, followed by the data collection with USD 274,601.

\section{Distribution of financial and economic costs - implementation phase}

Figures 2 and 3.

\section{Sensitivity analysis}

The sensitivity analysis revealed that varying the wage for informal workers from minimum to average wage did not have a major impact on the total economic costs. By applying this variation, the total economic costs only changed by USD $50,506(=4.2 \%)$ and amounted to USD 1,263,953 (Additional file 7). Varying the percentage of overhead costs also only had little impact on the total costs of the CBT intervention. More specifically, increasing the percentage of overhead costs $(16 \%$ for SERSAP and $22 \%$ for WB) led to an increase by USD 13,258 and amounted to a new economic value of USD 1,226,705. On the other hand, reducing the percentage of overhead costs $(10 \%$ for SERSAP and $18 \%$ for WB) resulted in a new economic value of USD 1,200,190 (Additional file 8). Varying the budget provided by SERSAP also impacted the overall economic value only marginally. Increasing the SERSAP budget (costs for personnel, equipment and the selection process) by $5 \%$ amounts to economic costs of USD $1,230,983$ by $10 \%$ to USD $1,248,517$; by $15 \%$ to USD $1,266,051$ and by $20 \%$ to USD $1,283,550$. Decreasing the SERSAP budget by $5 \%$ amounts to economic costs of USD $1,195,911$; by $10 \%$ to USD $1,178,377$; by $15 \%$ to USD $1,160,840$; and by $20 \%$ to USD $1,143,306$ (Additional file 9).

\section{Discussion}

This study is first of its kind to accurately trace both the financial and economic costs of CBT. By assessing the overall economic value of a CBT intervention, our study makes a unique contribution to the very limited literature available on the cost of targeting in general, both

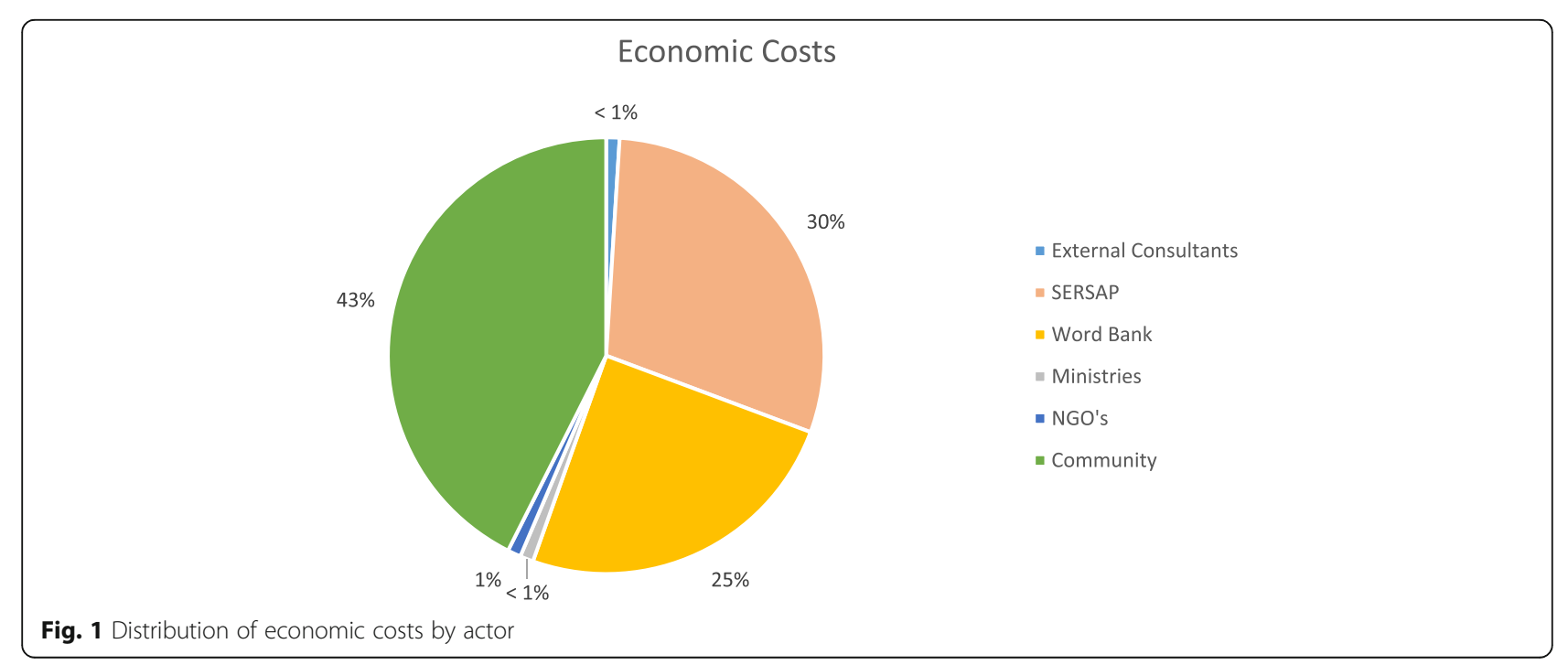


Table 3 Financial and economic costs - design phase by cost categories across activity clusters (in USD)

\begin{tabular}{|c|c|c|c|c|}
\hline Activity Cluster & Financial Costs & Percentage (\%) & Economic Costs & Percentage (\%) \\
\hline \multicolumn{5}{|c|}{ 1. General Coordination \& Management Design } \\
\hline Human Resources & 6348 & $85 \%$ & 44,754 & $71 \%$ \\
\hline Room Rental & 0 & $0 \%$ & 332 & $0.5 \%$ \\
\hline Transportation & 0 & $0 \%$ & 16,837 & $26,7 \%$ \\
\hline Consumables & 251 & $3 \%$ & 251 & $0.4 \%$ \\
\hline Overhead & 858 & $12 \%$ & 858 & $1.4 \%$ \\
\hline Grand Total & 7457 & $100 \%$ & 63,032 & $100 \%$ \\
\hline
\end{tabular}

within and beyond the health sector. The lack of comparable empirical literature seems to be due to the fact that the budget statements of targeting interventions in LMICs do not generally indicate costs by process or activity [11]. Lack of comparable studies limits our ability to discuss our results extensively in light of prior evidence, especially when considering the economic value of the intervention. Nevertheless, when relevant, we do appraise our findings in relation to the two published studies that assessed the financial costs of CBT $[18,19]$ and to the one unpublished report [11] which also accounted for the value of the time contributed by uncompensated community members.

A unique trait of our study is its reliance on $A B C$, a conceptual approach identified as the preferred one to cost complex health interventions, also in LMICs [35]. The application of $\mathrm{ABC}$ allowed us to estimate both the financial and economic costs of the CBT intervention per activity in a highly systematic and accurate manner. This high level of accuracy was ensured by the fact that instead of relying on financial statements as our primary source of information, we started our work by tracing all activities that made up the intervention and all resources consumed by these activities, looking for corresponding financial values only afterwards. Furthermore, combining $\mathrm{ABC}$ with Resource Consumption Accounting [36] allowed us to trace the single cost categories within each activity, generating a very detailed map for policy makers of what activities and what items within activities drove the intervention costs. It needs to be noted, however, that the application of this methodological approach is usually not inexpensive [31]. In our specific case, we could rely on $\mathrm{ABC}$ costing only because our access to all implementation documents was facilitated by our team's close relation with the implementation teams and its development partners.

We estimated a financial cost of USD 587,510 and an economic cost of USD 1,213,447 for the entire CBT intervention, including its design and implementation phase. With a total of 102,609 identified ultra-poor, this corresponds to a financial cost of USD 5.73 and an economic cost of USD 11.83 per ultra-poor person identified. As demonstrated in Additional files 2, 3 and 4 , our results were neither highly sensitive to variation of the applied wage nor to changes in the percentage of overhead costs or the budget provided by SERSAP. The consistency of our results from primary analysis with those of the sensitivity analysis suggests a good robustness of our findings.

Our study estimated financial costs per ultra-poor person identified to be within the same range of what was estimated in the few prior comparable studies. In particular, Ridde et al. [18], traced the financial expenses of a CBT action research project in one district of Burkina Faso and calculated financial cost of USD 10.16 per identified person. The financial costs Aryeetey et al. [19] calculated for a Participatory Wealth Ranking exercise in Ghana were calculated to be USD 3.83 per identified person in an urban setting, USD 10.63 for a rural setting and 2.71 for a semi-urban setting (calculation: survey costs without exemption premium divided by the total number of people exempted). Compared to the study of Watkins [11], who calculated financial cost of approximately USD 25 per recipient, our estimate is much lower. Differences are likely to be attributable to different implementation strategies as well to differences in methodological pathways to cost estimation.

Additionally, the study draws attention to the large discrepancy between financial and economic cost.Similarly to Watkins [11], we found the difference to be driven by the valuation of human resources, specifically the fact that we valued the time contributed towards the initiative by community volunteers. The heavy reliance on communities as key players in the implementation of the targeting intervention is well aligned with the push towards decentralization and community involvement, which has prevailed across sub-Saharan Africa following the Bamako Initiative [37]. Still this high reliance on communities as actual implementing agents raises important questions in terms of acceptability and feasibility. On the one hand, targeting of health services based on community-based approaches is likely to result in a more accurate and more acceptable identification strategy than one based on experts' (i.e. healthcare providers) judgment $[9,16,28,38]$ and is likely 
Table 4 Financial and economic costs - implementation phase by costs categories across activity clusters (in USD)

\begin{tabular}{|c|c|c|c|}
\hline & Activity Cluster & Financial Costs (in USD) & Economic Costs (in USD) \\
\hline \multirow[t]{38}{*}{ (II) Implementation Phase } & $\begin{array}{l}\text { 1. General Coordination \& Management } \\
\text { Implementation Phase }\end{array}$ & & \\
\hline & Human Resources & 18,751 & 45,408 \\
\hline & Room Rental & 126 & 358 \\
\hline & Transportation & 2472 & 15,409 \\
\hline & Consumables & 2002 & 2002 \\
\hline & Total & 23,351 & 63,177 \\
\hline & 2. Training & & \\
\hline & Human Resources & 44,408 & 117,895 \\
\hline & Room Rental & 5862 & 5862 \\
\hline & Transportation & 11,218 & 11,218 \\
\hline & Consumables & 24,809 & 24,849 \\
\hline & Total & 86,297 & 159,824 \\
\hline & 3. Selection of the ultra-poor & & \\
\hline & Human Resources & 71,386 & 378,284 \\
\hline & Room Rental & 0 & 0 \\
\hline & Transportation & 12,947 & 12,947 \\
\hline & Consumables & 829 & 829 \\
\hline & Total & 85,162 & 392,060 \\
\hline & 4. Data Collection & & \\
\hline & Human Resources & 133,591 & 274,601 \\
\hline & Room Rental & 0 & 0 \\
\hline & Transportation & 6463 & 6463 \\
\hline & Consumables & 47,894 & 47.894 \\
\hline & Total & 187,948 & 328,958 \\
\hline & 5. Card Production/Distribution & & \\
\hline & Human Resources & 0 & 7565 \\
\hline & Room Rental & 0 & 0 \\
\hline & Transportation & 0 & 1536 \\
\hline & Consumables & 107,000 & 107,000 \\
\hline & Total & 107,000 & 116,101 \\
\hline & 6. $M \& E$ & & \\
\hline & Human Resources & 8140 & 8140 \\
\hline & Room Rental & 0 & 0 \\
\hline & Transportation & 3199 & 3199 \\
\hline & Consumables & 0 & 0 \\
\hline & Total & 11,339 & 11,339 \\
\hline & Overhead & 78,956 & 78,956 \\
\hline & Grand Total Implementation Phase & 580,053 & $1,150,415$ \\
\hline
\end{tabular}

to be more attractive in the eyes of implementing agencies given its relatively low financial costs [11]. On the other hand, our study indicates that the time committed by volunteers has a clear opportunity cost, measured in terms of their foregone economic value. This observation questions the adequacy of executing CBT by adding an additional burden to communities already operating in resource-constrained settings and often struggling to meet their most basic needs [16, 38]. The challenge is that of relying on the expertise of communities, while at the same time offering 


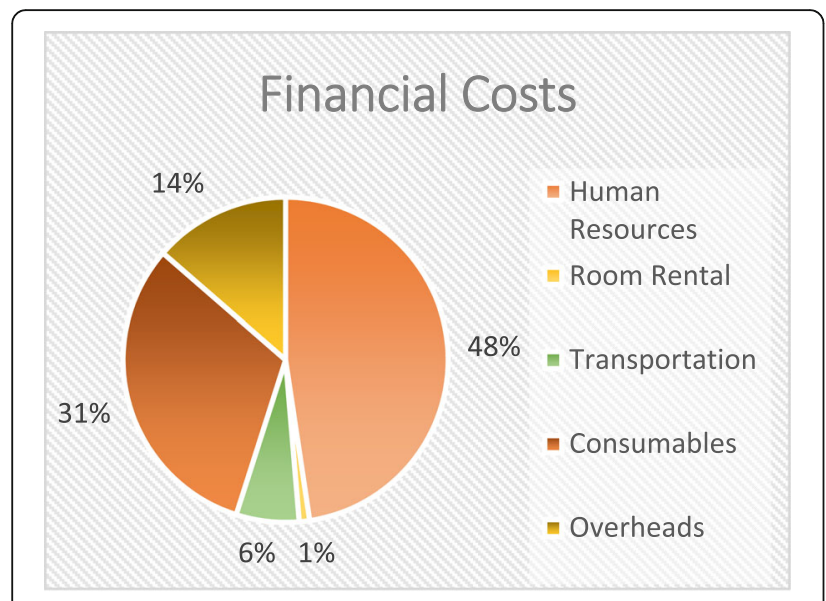

Fig. 2 Distribution of financial costs - Implementation Phase

adequate compensation for their engagement [39]. This is meant to sustain their motivation in contributing to such activities and avoid withdrawal during the implementation phase, as observed in some communities during the intervention described in our study [29].

Looking at the distribution of costs across activities provides additional evidence that financial and economic valuations do not necessarily align, as we see that the actual identification of the ultra-poor (the core activity delegated to communities) accounted for less than one sixth of all financial costs, but for one third of all economic costs. Moreover, the high cost associated with preparing for and producing identification cards may be surprising for those unfamiliar with the intervention, since the two activities combined accounted for nearly $50 \%$ of all financial costs. While we have been reassured by key stakeholders (personal communication) that the cost of card production was much lower in Vietnam compared to what it would have been in Burkina Faso, our appraisal of this specific set of findings inevitably

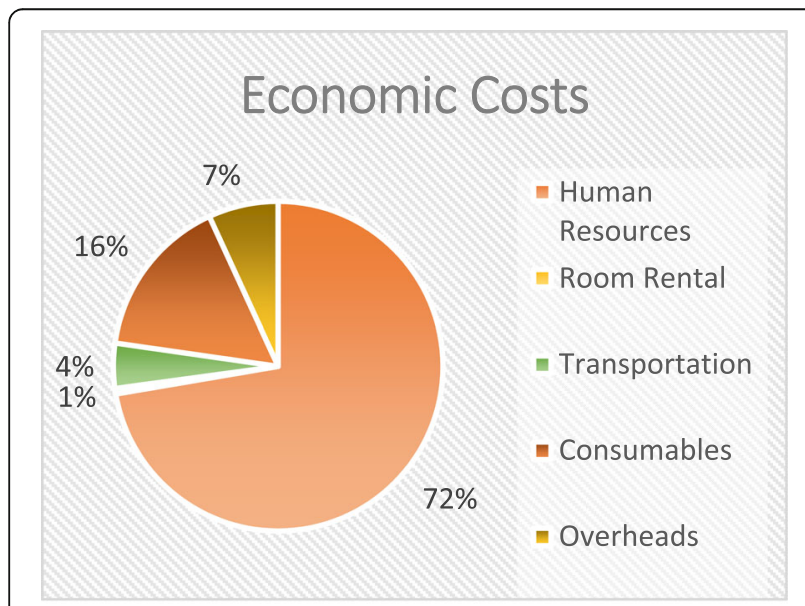

Fig. 3 Distribution of economic costs - Implementation Phase questions the need for sophisticated individual digitalized cards vs. simpler household traditional paper-based cards. It is beyond the scope of our work to assess the comparative advantage of a system based on digitalized vs. traditional paper-based identification cards, albeit we do imagine this to be a relevant area for further research, estimating cost-effectiveness of one system compared to the other. Likewise, the government and its partners, in Burkina as elsewhere, could test the possibility of lowering CBT costs by integrating activities related to the database establishment into the initial identification effort.

Furthermore, when assessing both the financial and the economic value of targeting interventions, one must consider the extent to which these are driven by national governments or by development partners [40]. In the specific case analyzed in our study, the largest portion of the financial costs $(60 \%)$, excluding the card production that was paid directly by the WB, were accrued by a local for-profit organization, SERSAP, which in turn was contracted by the governmental agency PADS. In practice, however, the resources deployed for the identification and selection procedure originated in a grant made by the HRITF to the government of Burkina Faso, channeled via the PADS. This explicit donor involvement sheds yet a different light on the appraisal of the financial costs associated with targeting programs. Spending close to USD 6 per ultra-poor person identified may be affordable for international agencies specifically committed to fostering greater equity in access, but is likely to be unaffordable for most LMICs, considering overall low levels of public spending on health [41]. Specifically, without aiming at conducting a full budget impact analysis - a task beyond our initial study objectives - it is worthwhile to appraise financial costs in relation to the overall health budget of Burkina Faso. The USD 5.73 per ultra-poor person identified are equivalent to $21 \%$ of Burkina Faso's per capita government expenditure on health (USD 27 (in PPP International USD, year: 2015)) [42]. At the same time, however, one must consider that targeting approaches are implemented beyond the health sector alone and hence there may be potential in sharing costs for pro-poor identification and selection procedures across sectors $[43,44]$.

\section{Methodological considerations}

We also faced some challenges during data collection and analysis, which are worthwhile discussing here as potential limitations of our study. First, we assessed the value of resources consumed by SERSAP activities on the basis of the unit costs and the units consumed as indicated in the initial implementation budgets rather than in the closing financial statements, to which we could not gain access. Hence, we cannot fully exclude having 
over or underestimated unit costs or resource consumption for some items. Nevertheless, given that we triangulated information coming from SERSAP documentation with information obtained during the key informant interviews, we are quite confident that we have not largely misestimated these values. Second, our analysis did not account for any fixed costs incurred at SERSAP as the agency was already operative and the targeting process only built upon it. This might have led to an underestimation of the full cost of CBT. Third, we must also mention that tracing all activities and all related resource consumption was difficult due to the retrospective nature of our study. It would have been desirable to conduct a prospective study which could have generated more accurate data [35] by applying the ABC-method from the onset. The retrospective nature of the study also opened the way to recall bias, since we interviewed key players about one year after cards were distributed.

\section{Conclusion}

Universal Health Coverage can only be achieved by ensuring that the poorest are not left behind. Thus, it is necessary that once implemented, measures to identify and address health inequity are systematically evaluated. With our study, we set the first example of how to systematically assess both the financial and economic costs of a community-based targeting program in a LMIC setting. We view the contribution of this costing study as meaningful, particularly because pro-poor targeting programs continue to expand, within and beyond the health sector. Future research should not only replicate this approach in other settings to generate additional and comparable evidence to better inform policy, but should also reach beyond the mere estimation of the costs to assess the costs of targeting in relation to the benefits accrued, within the framework of a comprehensive economic evaluation, such as a cost-effectiveness analysis.

\section{Additional files}

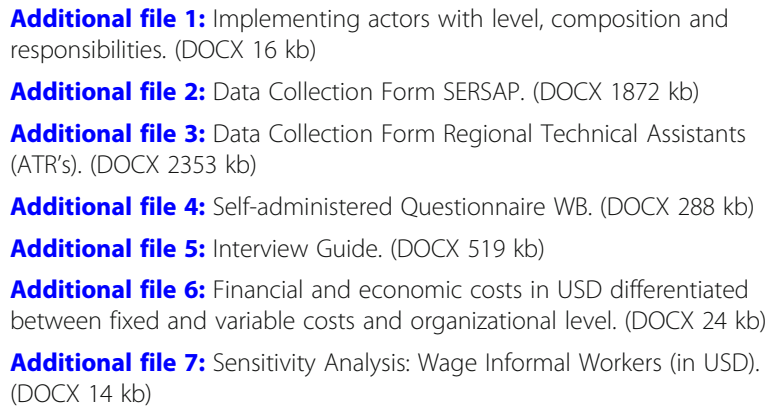

Additional file 9: Sensitivity Analysis: Increase and decrease SERSAP Budget (in USD). (DOCX $15 \mathrm{~kb}$ )

\section{Abbreviations}

ABC: Activity-based costing; ATRs: Assistant Technique Régional (Regional Technical Assistants); CBT: Community-based targeting; CNERS: Comité National d'Ethique pour la Recherche en Santé (Ethical Committee Burkina Faso); COGES: Comité de gestion (Management Committee); CSI: Comité de suivi de la sélection/cellule de sélection des indigents (Community Selection Committee); CSPS: Centre de Santé et de Promotion Sociale (Primary Health Care Centers); CSS: Comité de suivi de la sélection (Selection Monitoring Committee); ELMEO: Equipe Nationale de Mise En Fuvre/de coordination (Local Implementation Team); FCFA: Franc of the communauté financière Africaine (CFAF: Central French African Francs); GVL: Groupe de validation locale (Local Validation Group); HRITF: Health results innovation trust fund; ICP: Infirmier chef de poste (Head nurse); LMICs: Low and middle income countries; M\&E: Monitoring and evaluation; MoH: Ministry of health; MT: Means-test; NGOs: Non-governmental organizations; PADS: Programme d'Appui Au Développement Sanitaire (Health Development Support Program); PBF: Performance-based financing; PMT: Proxy means testing; SERSAP: Société d'Etude et de la Recherche en Santé Publique (Society for Studies and Public Health Research), Burkina Faso; USD: US-dollar; WB: World bank; WHO: World Health Organization

\section{Acknowledgements}

The authors are indebted to Dr. Aurelia Souares for her support with the application for ethical approval and to everyone in the implementation team across agencies for contributing their time towards data collection, specifically we to Haidara Ousmane Diadie and SERSAP staff. The authors are also grateful to Nathalie Camille Gemayel and Lydie Hochet-Weickert and for their support in translation and to Sarah Hanagarth for language editing of the final manuscript. We acknowledge financial support by Deutsche Forschungsgemeinschaft within the funding programme Open Access Publishing, by the Baden-Württemberg Ministry of Science, Research and the Arts and by Ruprecht-Karls- Universität Heidelberg.

\section{Funding}

Data collection and YB's position for the duration of the study were funded directly by the Research Group in Health Economics and Health Financing of the Institute of Public Health, Heidelberg University.

\section{Availability of data and materials}

Due to the possibility of identifying some respondents, the dataset compiling information across data sources cannot be made available open access. The authors are willing to share the database upon specific requests.

\section{Authors' contributions}

YB and MDA conceived the study and defined the study design and data collection strategy. YB coordinated data collection with support from MDA, JLK, PJR, and VR. YB analyzed the data, with support from MDA. All authors contributed to the interpretation of the data. YB drafted the initial manuscript with active writing contribution from all authors. All authors read and approved the final manuscript.

\section{Competing interests}

The authors declare that they have no competing interests. This costing study is not part of the impact evaluation commissioned by the World Bank to Heidelberg University and therefore was conducted as a fully independent research endeavor. The World Bank did not interfere with the study design, analysis, or interpretation of the data in any way.

\section{Publisher's Note}

Springer Nature remains neutral with regard to jurisdictional claims in published maps and institutional affiliations.

\section{Author details}

${ }^{1}$ Institute of Public Health, Medical Faculty, Heidelberg University, Heidelberg, Germany. ${ }^{2}$ RRD (French Institute for Research on Sustainable Development), CEPED (IRD-Université Paris Descartes), Universités Paris Sorbonne Cités, ERL INSERM, SAGESUD and University of Montreal, Public Health Research Institute (IRSPUM), Montréal, QC, Canada. ${ }^{3}$ The World Bank, Washington DC, USA. 


\section{Received: 6 April 2018 Accepted: 24 August 2018}

\section{Published online: 04 September 2018}

\section{References}

1. WHO. Universal health coverage (UHC) [Internet]. [cited 2017 Dec 4]. Available from: http://www.who.int/mediacentre/factsheets/fs395/en/.

2. Atchessi $\mathrm{N}$, Ridde $\mathrm{V}$, Zunzunégui $\mathrm{M}-\mathrm{V}$. Is the process for selecting indigents to receive free care in Burkina Faso equitable? BMC Public Health. 2014; 14(1):1158.

3. McKinnon B, Harper S, Kaufman JS, Bergevin Y. Removing user fees for facility-based delivery services: a difference-in-differences evaluation from ten sub-Saharan African countries. Health Policy Plan. 2014;30(4):432-41.

4. Bautista MCG, Yap MEC, Soriano ES. Local governments' health financing initiatives: evaluation, synthesis, and prospects for the national health insurance program in the Philippines. Partnerships for Health Reform, Abt Associates; 1999

5. Ridde V, Leppert G, Hien H, Robyn PJ, De Allegri M. Street-level workers' inadequate knowledge and application of exemption policies in Burkina Faso jeopardize the achievement of universal health coverage: evidence from a cross-sectional survey. Int J Equity Health 2018;17(1):5.

6. Alatas V, Banerjee A, Hanna R, Olken BA, Tobias J. Targeting the poor: evidence from a field experiment in Indonesia. Am Econ Rev. 2012;102(4): 1206-40.

7. Culyer AJ. Need: the idea won't do-but we still need it. Soc Sci Med. 1995; 40(6):727-30.

8. Hanson K, Worrall E, Wiseman V. Targeting services towards the poor: a review of targeting mechanisms and their effectiveness. 2007;

9. Devereux S, Masset E, Sabates-Wheeler R, Samson M, Rivas A-M, te Lintelo D. The targeting effectiveness of social transfers. J Dev Eff. 2017 ; 9(2):162-211.

10. Mkandawire T, UNRISD. Targeting and universalism in poverty reduction United Nations Research Institute for Social Development Geneva; 2005.

11. Watkins B. Alternative methods for targeting social assistance to highly vulnerable groups. A Report Prepared by Kimetrica for Care International; 2008.

12. Gilson L, Russell S, Buse K. The political economy of user fees with targeting: developing equitable health financing policy. J Int Dev. 1995;7(3):369-401.

13. Sen A. The political economy of targeting. In: Van de Walle D, Nead K, editors. Public spending and the poor : theory and evidence. Published for the World Bank by the Johns Hopkins University press; 1995. p. 11-24

14. Castro-Leal F, Dayton J, Demery L, Mehra K. Public spending on health care in Africa: do the poor benefit? Bull World Health Organ. 2000;78(1):66-74.

15. Mkandawire T. Targeting and universalism in poverty reduction. United Nations Research Institute for Social Development Geneva; 2005.

16. Conning J, Kevane M. Community-based targeting mechanisms for social safety nets: a critical review. World Dev. 2002;30(3):375-94.

17. Coady D, Grosh M, Hoddinott J. Targeting outcomes redux. World Bank Res Obs. 2004;19(1):61-85.

18. Ridde V, Yaogo M, Kafando Y, Sanfo O, Coulibaly N, Nitiema P, et al. A community-based targeting approach to exempt the worst-off from user fees in Burkina Faso. J Epidemiol Community Health. 2010;64(01):10-5.

19. Aryeetey GC, Jehu Appiah C, Spaan E, Agyepong I, Baltussen R. Costs, equity, efficiency and feasibility of identifying the poor in Ghana's Nationa Health Insurance Scheme: empirical analysis of various strategies. Tropical Med Int Health. 2012;17(1):43-51.

20. Ridde V, Haddad S, Nikiema B, Ouedraogo M, Kafando Y, Bicaba A. Low coverage but few inclusion errors in Burkina Faso: a community-based targeting approach to exempt the indigent from user fees. BMC Public Health. 2010;10:631.

21. Jehu Appiah C, Aryeetey G, Spaan E, Agyepong I, Baltussen R. Efficiency, equity and feasibility of strategies to identify the poor: an application to premium exemptions under National Health Insurance in Ghana. Health Policy. 95(2):166-73.

22. Coady D, Grosh ME, Hoddinott J. Targeting of transfers in developing countries: review of lessons and experience, vol. 1. Washington, DC: World Bank Publications; 2004.

23. Honda A, Hanson K. Do equity funds protect the poor? Case studies from North-Western Madagascar. Health Policy Plan. 2013;28(1):75-89.

24. World Bank. Burkina Faso - Reproductive Health Project: additional financing [Internet]. The World Bank; 2016 Feb [cited 2018 Jan 29] p. 1-55. Report No.: PAD1649. Available from: http://documents.worldbank.org/curated/en/
688901468187136539/Burkina-Faso-Reproductive-Health-Project-additionalfinancing.

25. SERSAP. Mise En Oeuvre et Suivi D'un Processus Communautaire de Sélection Des Indigents Dans 12 Districts Sanitaires Au Burkina Faso. Ouagadougou: SERSAP; 2014.

26. Ridde V, Turcotte-Tremblay A-M, Souares A, Lohmann J, Zombré D, Koulidiati $J$, et al. Protocol for the process evaluation of interventions combining performance-based financing with health equity in Burkina Faso. Implement Sci. 2014;9(1):149.

27. World Bank. Burkina Faso Overview [Internet]. Burkina Faso Overview. 2017 [cited 2018 Jan 29]. Available from: http://www.worldbank.org/en/country/ burkinafaso/overview.

28. Ridde V, Yaogo M, Kafando Y, Kadio K, Ouedraogo M, Bicaba A, et al. Targeting the worst-off for free health care: a process evaluation in Burkina Faso. Res Implement Evid Based Pract Commun Based Addict Treat Programs Policy Program Implic. 2011;34(4):333-42.

29. SERSAP. Rapport de La selection des indigents Au Burkina Fas. Ouagadougou: SERSAP; 2015

30. Drummond M, Sculpher M, Torrance G, O'Brien B, Stoddart G. Methods for the economic evaluation of health care programmes. $N$ Y: Oxford University Press; 2005

31. Kaplan RS, Anderson SR. Time-Driven Activity-Based Costing [Internet] Harvard Business Review. 2004 [cited 2018 Feb 4]. Available from: https:// hbr.org/2004/11/time-driven-activity-based-costing.

32. Levin HM. Cost-effectiveness analysis. In: Carnoy M, editor. International encyclopedia of economics of education: Pergamon Press; 1995.

33. Government of Burkina Faso. Tableau : classement indiciaire applicable aux emplois de fonctionnaires d'Etat pour compter du 1er janvier 2016 [Internet]. 2015 [cited 2018 Feb 4]. Available from: http://www.sig.bf/2016/ 05/tableau-classement-indiciaire-applicable-aux-emplois-de-fonctionnairesdetat-pour-compter-du-1er-janvier-2016/.

34. Government of Burkina Faso. Décret n²006-655/PRES/PM/MTSS/MFB du 29 décembre 2006 fixant les salaires minima interprofessionnels garantis. [Internet]. 2006 [cited 2018 Feb 4]. Available from: http://www.llo.org/dyn/ natlex/natlex4.detail?p_lang $=$ fr\&p_isn $=75633 \& p \_c o u n t r y=B F A \& p \_c o u n t=578$.

35. Smith PG, Morrow RH, Ross DA (Eds.). Field trials of health interventions. Oxford: Oxford University Press; 2015. p. 323-37.

36. Perkins D, Stovall OS. Resource consumption accounting-where does it fit? J Appl Bus Res. 2011;27(5):41.

37. Lacouture A, Kadio K, Ridde V. Renforcement des systèmes de santé en Afrique - Renforcement de l'empowerment, la participation et l'appropriation communautaires. In: Audibert M, Kondji Kondji D, editors. Le développement sanitaire en Afrique francophone: enjeux et perspectives; 2015.

38. Robertson L, Mushati P, Skovdal M, Eaton JW, Makoni JC, Crea T, et al. Involving communities in the targeting of cash transfer programs for vulnerable children: opportunities and challenges(). World Dev. 2014;54:325-37.

39. Zoysa I, Cole KS. Remuneration of the community health worker: what are the options? World Health Forum. 1983:4:125-30.

40. Van Domelen J. Reaching the poor and vulnerable: targeting strategies for social funds and other community-driven programs. Netw HD Wash DC World Bank 2007;1-52. SP Discussion paper. No. 0711.

41. Mcintyre D, Meheus F, Røttingen J-A. What level of domestic government health expenditure should we aspire to for universal health coverage? Health Econ Policy Law. 2017;12(2):125-37.

42. WHO. Global Health Expenditure Database [Internet]. 2018 [cited 2018 Jan 24]. Available from: http://apps.who.int/nha/database/ViewData/Indicators/en.

43. World Bank. Identification for Development. Strategic Framework [Internet]. 2016 [cited 2018 Jan 4]. Available from: http://pubdocs.worldbank.org/en/ 179901454620206363/Jan-2016-ID4D-Strategic-Roadmap.pdf.

44. Kardan A. Streamlining targeting mechanisms and processes across national social protection programme. Developing a concept [Internet]. Oxford Policy Management; 2016 [cited 2018 Aug 31]. Available from: https:// docplayer.net/48790616-Streamlining-targeting-mechanisms-and-processesacross-national-social-protection-programmes.html 